\title{
Acidification treatment of lignin from sugarcane bagasse results in fractions of reduced polydispersity and high free-radical scavenging capacity
}

\author{
Lívia Beatriz Brenelli $^{\mathrm{a}, \mathrm{b}}$, Fernanda Mandelli ${ }^{\mathrm{a}, \mathrm{c}}$, Adriana Zerlotti Mercadante ${ }^{\mathrm{c}}$, \\ George Jackson de Moraes Rocha ${ }^{a}$, Silvana Aparecida Rocco ${ }^{\mathrm{d}}$, Aldo Felix Craievich ${ }^{\mathrm{e}}$, \\ Adilson Roberto Gonçalves ${ }^{a}$, Danilo da Cruz Centeno ${ }^{f}$, Mario de Oliveira Neto ${ }^{g}$, \\ Fabio Marcio Squina ${ }^{a, *}$
}

a Laboratório Nacional de Ciência e Tecnologia do Bioetanol (CTBE), Centro Nacional de Pesquisa em Energia e Materiais (CNPEM), Caixa Postal 6192, CEP

13083-970 Campinas, São Paulo, Brazil

b Instituto de Biologia, Universidade de Campinas (UNICAMP), CEP 13083-862 Campinas, São Paulo, Brazil

' Departamento de Ciências de Alimentos, Faculdade de Engenharia de Alimentos, Universidade de Campinas (UNICAMP), CEP 13083-862 Campinas, São Paulo, Brazil

${ }^{\mathrm{d}}$ Laboratório Nacional de Biociências (LNBIO), Centro Nacional de Pesquisa em Energia e Materiais (CNPEM), Caixa Postal 6192, CEP 13083-970 Campinas, São Paulo, Brazil

e Instituto de Física, Universidade de São Paulo, CEP 05508-900 São Paulo, Brazil

f Centro de Ciências Naturais e Humanas (CCNH), Universidade Federal do ABC, CEP 09606-070 São Bernardo do Campo, São Paulo, Brazil

${ }^{g}$ Departmento de Física e Biofísica, Institudo de Biociências, Universidade Estadual Paulista "Júlio de Mesquita Filho" (UNESP), CEP 18618-970 Botucatu, São Paulo, Brazil

\section{A R T I C L E I N F O}

\section{Article history:}

Received 22 May 2015

Received in revised form 1 December 2015

Accepted 7 December 2015

Available online 30 December 2015

\section{Keywords:}

Lignin

Sugarcane bagasse

Small-angle X-ray scattering

Reactive oxygen species

Reactive nitrogen species

\begin{abstract}
A B S T R A C T
Lignin constitutes up to one-third of the material found in plant cell walls and is considered the second most abundant natural polymer in the world. Despite unique characteristics of lignin, it is mostly used for low-value commercial applications. In this study, lignin obtained after alkaline treatment of steamexploded sugarcane bagasse was submitted to an acidification process. The soluble fractions produced at different $\mathrm{pH}$ values were comprehensively characterized and in vitro antioxidant capacity against reactive oxygen ( $\mathrm{ROO}^{\bullet}$ and $\mathrm{H}_{2} \mathrm{O}_{2}$ ) and nitrogen $\left(\mathrm{ONOO}^{-}\right.$) species was evaluated. The soluble fraction obtained at $\mathrm{pH}$ 2 exhibited the highest scavenging capacities against all species tested $(10.2 \pm 0.7 \mathrm{mmol}$ Trolox equivalent $\mathrm{g}^{-1}$ for $\mathrm{ROO}^{\bullet}, \mathrm{IC}_{30}=14.9 \mu \mathrm{g} \mathrm{mL}^{-1}$ for $\mathrm{H}_{2} \mathrm{O}_{2}$ and $\mathrm{IC}_{50}=2.3 \mu \mathrm{g} \mathrm{mL}^{-1}$ for $\mathrm{ONOO}^{-}$) and the lowest polydispersity value (1.2) compared to others fractions. According to the SAXS data, the soluble fractions obtained at $\mathrm{pH} 4$ and $\mathrm{pH} 2$ consisted of small nanometer-sized discs and low molecular weight polyphenolic clusters, while soluble fractions obtained at high $\mathrm{pH}$ predominated wide lignin nanoparticles and larger aggregates. Mass spectroscopy analysis revealed the presence of phenolic and non-phenolic compounds, well-known as efficient antioxidants, which were identified in all soluble fractions. Collectively, our results provided further demonstration that acidification treatment is a promising strategy to upgrade heterogeneous lignin-enriched stream from sugarcane bagasse, such as preparations with homogeneous compositions and high antioxidant activity.
\end{abstract}

(ㄷ) 2015 Elsevier B.V. All rights reserved.

Abbreviations: SCB, sugarcane bagasse; AT, alkaline treatment; SF, soluble fraction; ROS, reactive oxygen species; RNS, reactive nitrogen species; TPC, total phenolic

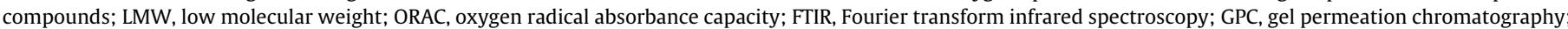

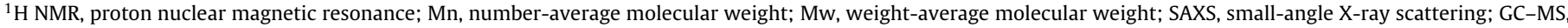
gas chromatography-mass spectrometry.

* Corresponding author at: Rua Giuseppe Máximo Scolfaro, 10.000; Polo de Alta Tecnologia, Caixa Postal 6170, Campinas, SP CEP: $13083-970$, Brazil. Fax +55 19 35183104.

E-mail addresses: livia.paiva@bioetanol.com.br (L.B. Brenelli), fernanda.mandelli@bioetanol.org.br (F. Mandelli), azmercadante@gmail.com (A.Z. Mercadante), george.rocha@bioetanol.org.br (G.J.d.M. Rocha), silvana.rocco@lnbio.cnpem.br (S.A. Rocco), craievich@if.usp.br (A.F. Craievich), adilson.goncalves@bioetanol.org.br (A.R. Gonçalves), danilo.centeno@ufabc.edu.br (D.d.C. Centeno), mario.neto@ibb.unesp.br (M. de Oliveira Neto), fabio.squina@bioetanol.org.br (F.M. Squina). 


\section{Introduction}

Sugarcane bagasse (SCB) is a renewable power generation source that provides energy to operate sugar and ethanol mills and bagasse-based bioelectricity, which is exported to the national grid (Bizzo et al., 2014). Furthermore, this lignocellulosic material has been considered promising resource to produce biofuel and others value-added products because of the relatively low cost, great abundance and low environmental impact (Mandelli et al., 2014; Chundawat et al., 2011).

The biofuel production from SCB usually requires pretreatment and delignification steps, to separate lignin and hemicellulose from cellulose and reduce the crystallinity and enzymatic recalcitrance of plant biomass polysaccharides (Martínez et al., 2015; Benjamin et al., 2013; Kuo and Lee, 2009). Most of the available SCB pretreatment technologies for ethanol production (e.g organosolv, hydrothermal, dilute acid and alkaline) often produce a large amount of lignin stream as major residue (Carvalho et al., 2015; Dias et al., 2009). During lignocellulose pretreatment, lignin is generally extracted under conditions in which is progressively broken down into lower molecular weight (LMW) fragments, resulting in considerable changes in physicochemical properties. Consequently, apart from the lignocellulosic biomass, lignin isolation procedure also affects the structure and purity of the final material (Doherty et al., 2011).

Lignin often constitutes up to one-third of the material found in plant cell walls and the second most abundant natural polymer in the world. This aromatic polymer is a complex polymeric and amorphous structure arising from the enzymatic dehydrogenative polymerization of coniferyl, sinapyl and p-coumaryl alcohol (Ayyachamy et al., 2013), although this proportion can vary depending on the source. Despite lignin's unique characteristics, it is mostly used for low-value commercial applications, such as combusted for energy production, and considered untapped biopolymers in biomass conversion technologies (Ayyachamy et al., 2013; Doherty et al., 2011).

There are several studies demonstrating that lignin can serve as renewable resource for aromatic compounds with antioxidant capacity (García et al., 2010; Vinardell et al., 2008; Pan et al., 2006). The recently literature has reported that the antioxidant capacity of lignin fractions from steam-exploded bamboo stems and SCB are higher than the synthetic antioxidant dibutylhydroxytoluene(BHT) (Kaur and Uppal, 2015; Sun et al., 2014).

Because of its high content of diverse functional groups (e.g., phenolic and aliphatic hydroxyls, carbonyls, and carboxyls) and phenylpropanoic structure, lignin can act as a neutralizer or inhibitor in oxidation processes and stabilize reactions that are induced by oxygen radicals and derivatives thereof (Randhir et al., 2004). Nevertheless, the antioxidant capacity of lignins significantly depends on the lignocellulosic material and isolation method employed (Ponomarenko et al., 2015; Li and Ge, 2012; Dizhibite et al., 2004).

A number of studies have shown that high chemical heterogeneity of lignin, including differences in lignin macromolecule chemical structure, functionality and molecular mass distribution, can turn impractical its applicability as antioxidant in targeted systems (Ponomarenko et al., 2015; Bikova et al., 2004). Recently, it was reported different strategies to obtain homogeneous lignin fractions with antioxidant activity, such as acid precipitation (dos Santos et al., 2014; Ma et al., 2013; Faustino et al., 2010) and sequential solvent fractionation (Ponomarenko et al., 2015; Cui et al., 2014; Li et al., 2012). The acid precipitation approach is based on differences in either solubility or molecular weight of lignins and it has been widely employed since 1960s for Kraft black liquor (Wada et al., 1962).
The expansion of commercial lignocellulosic biorefineries based on the enzymatic deconstruction of plant polysaccharides will increase the production of lignin-rich streams (Ragauskas et al., 2014). Based on projected scenarios for integrating first- and second-generation ethanol production processes in Brazil, with the electrical cogeneration system, lignin streams are currently considered fuel for boilers to supply the required energy power to run plants (Dias et al., 2013). Thus, the development of strategies for fully exploiting the potential of lignin is necessary to overcome the economic and sustainability challenges associated with the use of lignocellulose in the bio-product value chain.

This work focused on studying lignin derived from SCB after steam explosion and alkaline treatment (AT lignin), which is a consistent stream from the second-generation bioethanol pilot-scale study in Brazil (Rocha et al., 2012a,b). This AT lignin was submitted to a simple acidification method for dissolving the heterogeneous lignin mixture to generate soluble fractions with low polydispersity, similar phenolic compositions and high antioxidant capacity. In this study, the structural features of the soluble fractions were comprehensively investigated by different techniques, as well as, the in vitro antioxidant capacity against reactive oxygen ( $\mathrm{ROO}^{\bullet}$ and $\left.\mathrm{H}_{2} \mathrm{O}_{2}\right)$ and nitrogen $\left(\mathrm{ONOO}^{-}\right)$species were also evaluated.

\section{Methods}

\subsection{Raw material}

Lignin extracted from steam-exploded SCB with $\mathrm{NaOH} 1 \%(\mathrm{w} / \mathrm{v})$ was provided by The Engineering School of Lorena (EEL-USP) and the process is described in detail in Rocha et al. (2012b). The material was named in this study as AT lignin (Alkaline Treatment).

\subsection{Purity analysis and acid-insoluble and acid-soluble lignin determination}

The impurities in the AT lignin (starting material) were defined as ash content (inorganic material), sugars (cellobiose, xylose, glucose, arabinose and galactose), acetic acid furfuraldehyde and hydroxymethylfurfural content. For ash analysis crucibles were pre-dried to constant weight in a muffle furnace at $575^{\circ} \mathrm{C}$. The AT lignin samples were weighed into the crucibles and heated to $100^{\circ} \mathrm{C}$ to remove moisture. The crucibles were subsequently heated at $300^{\circ} \mathrm{C}$ for $2 \mathrm{~h}$ and $800^{\circ} \mathrm{C}$ for $2 \mathrm{~h}$ to constant weight (ASTM Methods, 1966). The weight of the remaining ash was calculated as a percentage of the original dry weight of the sample. For insoluble and soluble lignin determination, carbohydrates, acetic acid and furfuraldehyde/hydroxymethylfurfural determination, approximately $2 \mathrm{~g}$ of AT lignin was treated with $10 \mathrm{~mL}$ of $72 \%$ sulfuric acid under vigorous mixing for $7 \mathrm{~min}$ in a bath at $45^{\circ} \mathrm{C}$ (Gouveia et al., 2009). The reaction was interrupted thought the addition of $275 \mathrm{~mL}$ of distilled water and the solution was autoclaved for $15 \mathrm{~min}$ at 1.05 atmand $121^{\circ} \mathrm{C}$ to complete the oligomer hydrolysis. The hydrolyzed material was separated from solids through filtration using a paper filter (Nalgon, $18.5 \mathrm{~cm}$ diameter) previously weighed. The solid in the paper filter was washed with distilled water which was added in the hydrolysate stored for further analysis. The lignin retained in paper filter was dried in oven at constant temperature of $105^{\circ} \mathrm{C}$ and the content was obtained by gravimetry. Soluble lignin in the hydrolysate was determined by UV spectroscopy as previously described (Rocha et al., 2012a). The results reported as a percentage of the original dry weight of the sample. Sugars, acetic acid and furfuraldehyde/hydroxymethylfurfural content in the hydrolysate were determined through high performance liquid chromatography (HPLC) as described in Rocha et al. (2012a) and reported as a percentage of the original dry weight of the sample. 


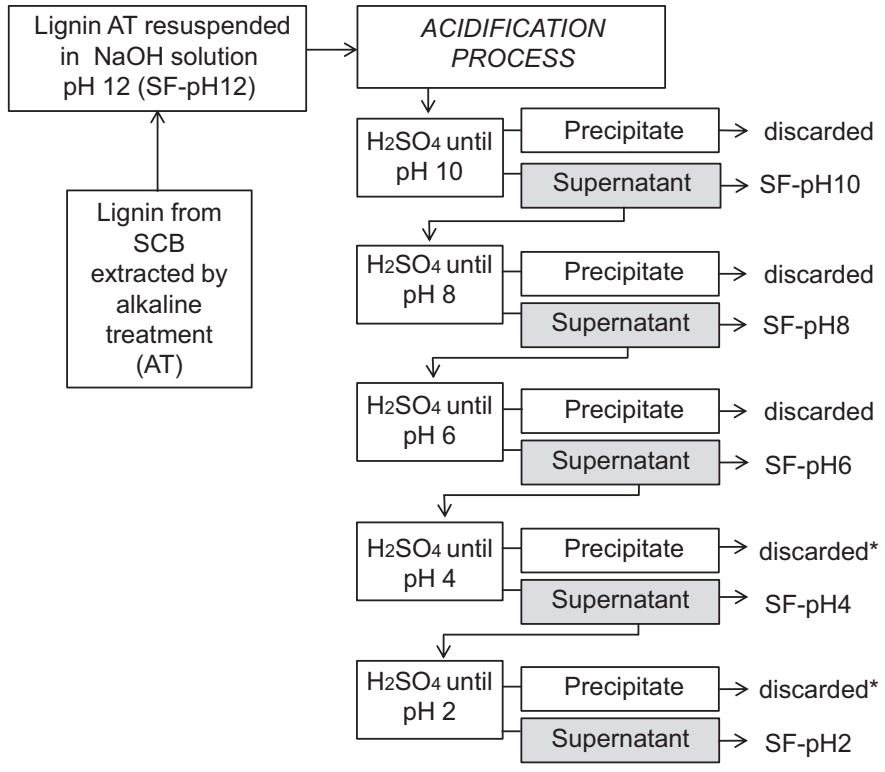

Fig. 1. Scheme for the acidification process protocol of lignin. *Large amount of precipitate was observed at $\mathrm{pH} 4$ and 2 .

\subsection{Acidification treatment}

AT lignin acidification treatment was achieved by adding sulfuric acid (Fig. 1) in order to obtain the soluble fractions (SF) in different $\mathrm{pH}$ conditions. Approximately $20 \mathrm{~g}$ of AT lignin was dissolved in $2 \mathrm{~L}$ of $\mathrm{NaOH}$ aqueous solution $\left(400 \mu \mathrm{L} \mathrm{NaOH} 10 \mathrm{~mol} \mathrm{~L}^{-1}\right.$ in $2 \mathrm{~L}$ distilled water) at $\mathrm{pH} 12$ (SF-pH12). Sulfuric acid $1 \mathrm{~mol} \mathrm{~L}^{-1}$ was slowly added to SF-pH12 under stirring until reaching a $\mathrm{pH}$ value of 10 . The $\mathrm{pH}$ value was allowed to stabilize for $30 \mathrm{~min}$. The solution was centrifuged at $1878 \times \mathrm{g}$ for $20 \mathrm{~min}$ at $4{ }^{\circ} \mathrm{C}$, and the supernatant (soluble fraction) separated from the precipitate (discarded). An aliquot $(200 \mathrm{~mL})$ was removed from the supernatant and named SF-pH10. The same procedure was conducted to the remainder of the solution to obtain SF-pH8, SF-pH6, SF-pH4 and SF-pH2. The pH value stabilization was allowed to stabilize for $30 \mathrm{~min}$, and the $\mathrm{pH}$ value was adjusted if necessary. All aliquot fractions were dried at $30^{\circ} \mathrm{C}$ under normal atmosphere. Dry powdered fractions were used for further analysis. The concentration of soluble lignin was determined using UV-spectroscopy as previously described (Rocha et al., 2012a).

\subsection{Determination of the phenolic hydroxyl content}

The phenolic hydroxyl content was determined using the differential scanning UV-spectroscopy method adapted based on the average absorptivity of the model lignin compounds (Wexler, 1964). A solution was prepared by diluting $1 \mathrm{~mL}$ of lignin solution $\left(20 \mathrm{mg} \mathrm{mL}^{-1}\right)$ in $10.0 \mathrm{~mL}$ of dioxane $50 \%(\mathrm{v} / \mathrm{v})$. The $\mathrm{pH}$ values of the solutions were adjusted to 14 with sodium hydroxide $\left(1 \mathrm{~mol} \mathrm{~L}^{-1}\right)$. A blank of each sample was prepared in the same dilution at $\mathrm{pH}$ 1 using hydrochloric acid $\left(1 \mathrm{~mol} \mathrm{~L}^{-1}\right)$. The sweep of the alkaline solution against the acid solution was performed. The results were expressed in percentage of phenolic hydroxyl. Eq. (1) describes the phenolic hydroxyl content determination.

$\% \mathrm{OH}-\mathrm{Ph}=\frac{\left(\Delta \mathrm{Abs}_{250 \mathrm{~nm}} \times 0.192\right)}{\mathrm{Clig}}$

where\%OH-Ph $=$ phenolic hydroxyl content in percentage; $\Delta \mathrm{Abs}_{250 \mathrm{~nm}}=$ absorbance of the solution at $250 \mathrm{~nm}$ subtracted from the relative absorbance of the baseline spectrum; Clig=Lignin concentration in $\mathrm{gL}^{-1}$.

\subsection{Fourier transform infrared spectroscopy (FTIR) analysis}

Dry powdered fractions were dissolved in pure chloroform, filtered using a paper filter and dried at $30^{\circ} \mathrm{C}$ under normal atmosphere to eliminate the sodium sulphate formed during the acidification treatment. The FTIR analyses were performed using a PerkinElmer FTIR Spectrum ${ }^{\mathrm{TM}} 400$ Series FT-IR/FT-NIR, which was equipped with Attenuated total reflectance (ATR) and zinc selenide. The spectral resolution of the apparatus was $4.0 \mathrm{~cm}^{-1}$. For each sample, 32 spectra were accumulated in the range of $500-4000 \mathrm{~cm}^{-1}$ and averaged. The region between $1900 \mathrm{~cm}^{-1}$ and $1850 \mathrm{~cm}^{-1}$ was chosen for normalization procedure.

\subsection{Proton nuclear magnetic resonance $\left({ }^{1} \mathrm{H} N \mathrm{NR}\right)$ analysis}

Approximately $100 \mathrm{mg}$ of lignin was acetylated in $2 \mathrm{~mL}$ of an acetic anhydride: pyridine solution $(1: 1, v / v)$, which was kept at room temperature for $18 \mathrm{~h}$ under stirring. After stripping with chloroform, pyridine was removed with hydrochloric acid solution (7\%) and water. The samples were dried in vacuum and solubilized in $\mathrm{CDCl}_{3}$, which contained TMS $1 \%$ (tetramethylsilane). The quantitative ${ }^{1} \mathrm{H}$ NMR spectra of the lignin fractions were recorded on an Agilent DD2 spectrometer operating at a Larmor frequency of $499.726 \mathrm{MHz}$ at $25^{\circ} \mathrm{C}$. The parameters for data acquisition were: pulse width of $10.250^{\circ}$, spectral window of $8000 \mathrm{~Hz}$, and 256 time increments were recorded. The spectra were calibrated based on the signal from TMS.

\subsection{Gel permeation chromatography (GPC) analysis}

The number-average molecular weight (Mn) and weightaverage molecular weight (Mw) of acetylated lignin fractions were evaluated in a Shimadzu apparatus, which was equipped with a UV detector and an auto sampler. The samples were injected onto a series of three PLGel $\left(500,10^{3}\right.$ and $10^{4} \AA$ ) columns including a guard column, eluted at $35^{\circ} \mathrm{C}$, a pressure of $71 \mathrm{kgf} \mathrm{cm}^{-2}$, a flow rate of $1 \mathrm{~mL} \mathrm{~min}{ }^{-1}$ of tetrahydrofuran (THF) and detected at $280 \mathrm{~nm}$. The injection volume was $50 \mu \mathrm{L}$, and the concentration of the injected solutions, whether they contained standards or samples, was fixed at $40 \mathrm{mg}$ of material dissolved in $1 \mathrm{~mL}$ of THF. Standard polystyrene (Sigma-Aldrich) samples were used to construct a calibration curve (molecular weight range from $350 \mathrm{kDa}$ to $165 \mathrm{Da}$ ). The average molar mass (M) of a polydispersed polymer results from several possible methods that average different present species according to Eq. (2).

$M=\frac{\left(\Sigma \mathrm{NiMi}^{n+1}\right)}{\Sigma\left(\mathrm{NiMi}^{n}\right)}$

Due to the differences in chemical structure between the lignins and polyphenols and the calibration polystyrene standards, the data only represent the relative Mw and Mn.

\subsection{Small-angle $X$-ray scattering (SAXS)}

SAXS measurements of all studied soluble fractions were conducted at the D02A-SAXS2 beam line of the Brazilian Synchrotron Light Laboratory, Campinas, Brazil. The SF-pH4 and 2 fractions were purified to eliminate impurities using a Superdex 30 Pep Grade and $\mathrm{NaOH} 0.1 \mathrm{~mol} \mathrm{~L}^{-1}$ as eluent.

Soluble fractions were studied by SAXS using a monochromatic X-ray beam (wavelength $\lambda=1.55 \AA$ ). 2D X-ray patterns were recorded by a two-dimensional CCD X-ray detector (MarResearch, USA). The sample-to-detector distance was set at $1000 \mathrm{~mm}$, thus allowing for a modulus of accessible scattering vector ranging from $q=0.14 \mathrm{~nm}^{-1}$ up to $3.4 \mathrm{~nm}^{-1}, q=4 \Pi \sin \theta / \lambda$, where $\theta$ is half the scat- 
tering angle. All soluble fractions were prepared in aqueous 10\% $(\mathrm{m} / \mathrm{v}) \mathrm{NaOH}$ solution seven days prior to SAXS analyses (Maziero et al., 2012). The SAXS intensity curves were determined under several dilution conditions thus yielding three different lignin solutions at $2.5,5$ and $10 \mathrm{~g} \mathrm{~L}^{-1}$.

For SAXS measurements, lignin solutions and solvent were successively placed in a sample cell with two thin parallel windows $\left(1 \mathrm{~mm}\right.$ of path length) maintained at approximately $25^{\circ} \mathrm{C}$. Two successive frames of $300 \mathrm{~s}$ each were recorded for each sample to evaluate eventual effects of radiation damage and X-ray beam instabilities.

The experimental SAXS patterns were corrected for detector response and normalized to equivalent incident beam intensity, samples absorption and lignin concentration. The background (solvent + parasitic) scattering intensity was subtracted from the total intensity curves. The recorded isotropic 2D SAXS patterns were integrated to obtain 1D scattering intensity, $I(q)$, by using the Fit2D software (Hammersley, 1997). The fitting analysis using modelled SAXS intensities that allowed us to determine relevant structural parameters of all soluble lignin fractions was performed by applying the SASFIT package (Kohlbrecher, 2006).

\subsection{Determination of the total phenolic compounds (TPC)}

The Folin-Ciocalteu colorimetric method of Singleton(Singleton et al., 1999) was adapted to a microplate reader (Synergy Mx; Biotek, USA) for TPC determination. The reaction mixtures in the sample wells contained the following reagents: $150 \mu \mathrm{L}$ of ultrapure water, $25 \mu \mathrm{L}$ of soluble fractions in different concentrations and $25 \mu \mathrm{L}$ of the Folin-Ciocalteu reagent. The mixture was incubated in the microplate reader, shaken for $20 \mathrm{~s}$, and maintained at $25^{\circ} \mathrm{C}$ for $5 \mathrm{~min}$. This process was followed by adding $100 \mu \mathrm{L}$ of a $7 \%$ sodium carbonate solution. The absorbance signal was measured after $2 \mathrm{~h}$ at a wavelength of $765 \mathrm{~nm}$. The results were expressed in milligrams of gallic acid equivalent per gram of lignin.

\subsection{Reactive oxygen and nitrogen species scavenging (ROS and RNS) assays}

A microplate reader equipped with a thermostat (Synergy HT, Biotek, Vermont, USA) for fluorescence and chemiluminescence measurements was used for all assays. Each ROS- and RNS-scavenging result corresponds to five concentrations and was performed in triplicate.

\subsubsection{Peroxyl radical scavenging assay}

The ROO• scavenging capacity was measured by monitoring the effect of the soluble fractions on the fluorescence decay resulting from $\mathrm{ROO}^{\bullet}$-induced oxidation of fluorescein, using the oxygen radical absorbance capacity (ORAC) method (Rodrigues et al., 2013). ROO ${ }^{\bullet}$ was generated by the thermodecomposition of $\alpha, \alpha^{\prime}$-azodiisobutyramidine dihydrochloride (AAPH) at $37^{\circ} \mathrm{C}$. The reaction mixtures in the wells contained the following reagents at the indicated final concentrations (final volume of $200 \mu \mathrm{L}$ ): fluorescein $\left(61 \mathrm{nmol} \mathrm{L}^{-1}\right)$, AAPH solution in phosphate buffer $\left(19 \mathrm{mmol} \mathrm{L}^{-1}\right)$ and soluble fractions in different concentrations. The mixture was preincubated in the microplate reader for $10 \mathrm{~min}$ before the addition of AAPH. The fluorescence signal was monitored every minute for the emission wavelength of $528 \pm 20 \mathrm{~nm}$ with excitation at $485 \pm 20 \mathrm{~nm}$ over a period of $180 \mathrm{~min}$. Trolox was used as the positive control (Net area $\left(64 \mu \mathrm{mol} \mathrm{L}^{-1}\right)=23$ ). Briefly, the net protection provided by the extracts or Trolox (standard) was calculated using the difference between the area under the fluorescence decay curve in the presence of the sample (area under the curve $\left.\mathrm{AUC}_{\text {extract }}\right)$ and in its absence $\left(\mathrm{AUC}_{\mathrm{blank}}\right)$. Regression equations between the net AUC and the sample concentrations were calculated for all extracts and Trolox. The results of the peroxyl radical scavenger capacity of the extracts were expressed as Trolox equivalents in micromoles per gram of lignin.

\subsubsection{Hydrogen peroxide scavenging assay}

The $\mathrm{H}_{2} \mathrm{O}_{2}$ scavenging capacity of soluble fractions was measured by monitoring the $\mathrm{H}_{2} \mathrm{O}_{2}$-induced oxidation of lucigenin (Gomes et al., 2007). Reaction mixtures contained the following reagents at the final concentrations (final volume of $300 \mu \mathrm{L}$ ): $50 \mathrm{mmol} \mathrm{L}^{-1}$ Tris $\mathrm{HCl}$ buffer $(\mathrm{pH} 7.4)$, lucigenina solution in Tris $\mathrm{HCl}$ buffer $\left(0.8 \mathrm{mmol} \mathrm{L}^{-1}\right), 1 \%(\mathrm{w} / \mathrm{w}) \mathrm{H}_{2} \mathrm{O}_{2}$ and lignin in different concentrations or Trolox (five concentrations). The chemiluminescence signal was detected in the microplate reader after 5 min of incubation. Ascorbic acid was used as the positive control. The results were expressed as the inhibition in percentage $\left(\mathrm{IC}_{30}\right)$ of the $\mathrm{H}_{2} \mathrm{O}_{2}$ induced oxidation of lucigenin.

\subsubsection{Peroxynitrite scavenging assay}

The $\mathrm{ONOO}^{-}$scavenging capacity was measured by monitoring the $\mathrm{ONOO}^{-}$-induced oxidation of non-fluorescent dihydrorhodamine (DHR) to fluorescent rhodamine (Gomes et al., 2007). $\mathrm{ONOO}^{-}$was synthesized as previously described (Beckman et al., 1994). The reaction mixtures contained the following reactants at the indicated final concentrations (final volume of $300 \mu \mathrm{L}$ ): DHR $\left(5 \mu \mathrm{mol} \mathrm{L}^{-1}\right), \mathrm{ONOO}^{-}\left(600 \mathrm{nmol} \mathrm{L}^{-1}\right)$ and lignin in different concentrations or Trolox (five concentrations). The fluorescence signal was measured in the microplate reader after $5 \mathrm{~min}$ of incubation at emission and excitation wavelengths of $528 \pm 20 \mathrm{~nm}$ and $485 \pm 20 \mathrm{~nm}$, respectively. The assays were performed in the presence of $25 \mathrm{mmol} \mathrm{L}^{-1} \mathrm{NaHCO}_{3}$ to simulate the physiological $\mathrm{CO}_{2}$ concentration once under physiological conditions; the reaction between $\mathrm{ONOO}^{-}$and bicarbonate is predominant $\left(k=3-5.8 \times 10^{4} \mathrm{M}^{-1} \mathrm{~s}^{-1}\right)$, which generated nitrogen dioxide $\left(\mathrm{NO}_{2}{ }^{\circ}\right)$ and carbonate radical anion $\left(\mathrm{CO}_{3}{ }^{-}\right)$. Ascorbic acid was used as the positive control $\left(\mathrm{IC}_{50}=0.31 \mu \mathrm{g} \mathrm{mL}^{-1}\right.$ ). The results were expressed as the inhibition in percentage $\left(\mathrm{IC}_{50}\right)$ of the $\mathrm{ONOO}^{-}$-induced oxidation of non-fluorescent DHR to fluorescent rhodamine.

\subsection{Gas chromatography/mass spectrometry analysis (GC-MS)}

The profile of soluble fractions was performed with derivatized samples by a GC-MS system (Agilent GC 6890 and MSD 5973 N series, Agilent, USA), according to Suguiyama et al. (2014). The samples were derivatized with $200 \mu \mathrm{L}$ of pyridine and $50 \mu \mathrm{L}$ of N,O-bis[trimethylsilyl] trifluoroacetamide (BSTFA), shaken carefully and placed on a heating block at $75^{\circ} \mathrm{C}$ for $1 \mathrm{~h}$ (tubes were shaken every $10 \mathrm{~min}$ in vortex). The samples were transferred to a crimp-cap GC vial and submitted for analysis. GC was performed on a $30 \mathrm{~m}$ DB-1701 column with $0.25 \mu \mathrm{m}$ film thickness (Agilent Technologies, USA). The injection temperature was set at $230^{\circ} \mathrm{C}$, the interface at $250^{\circ} \mathrm{C}$, and the ion source adjusted to $150^{\circ} \mathrm{C}$. Helium was used as the carrier gas at a flow rate of $1 \mathrm{~mL} \mathrm{~min}^{-1}$. The analysis was performed under the following temperature program: $5 \mathrm{~min}$ of isothermal heating at $70^{\circ} \mathrm{C}$, followed by a $5^{\circ} \mathrm{C} \mathrm{min}^{-1}$ oven temperature ramp to $310^{\circ} \mathrm{C}$, and a final $1 \mathrm{~min}$ of heating at $280^{\circ} \mathrm{C}$. Mass spectra were recorded at 2 scan s$^{-1}$ with a scanning range of $50-600 \mathrm{~m} / \mathrm{z}$. Both chromatograms and mass spectra were evaluated using the Chem Station program (Agilent Technologies, USA) and the software AMDIS (NIST, USA). The peaks were identified and quantified in comparison with authentic standards and the NIST Mass Spectral Library.

\subsection{Correlations and statistical analysis}

Triplicate analyses of the samples were performed throughout the experiments. Statistical analyses were performed using the 
Table 1

Chemical and physical properties and scavenging capacities of soluble fractions.

\begin{tabular}{|c|c|c|c|c|c|c|c|c|c|c|}
\hline \multirow[b]{2}{*}{ Sample } & \multirow[b]{2}{*}{$\begin{array}{l}\text { Soluble fraction } \\
\text { yield (\%) }\end{array}$} & \multicolumn{6}{|c|}{ Chemical and physical properties } & \multicolumn{3}{|c|}{ Scavenging capacities $^{* * *}$} \\
\hline & & $\begin{array}{l}\text { Soluble fraction } \\
\text { concentration } \\
\left(\mathrm{g} \mathrm{L}^{-1}\right)\end{array}$ & $\begin{array}{l}\text { Phenolic } \\
\text { Hydroxyl } \\
\text { content }^{*}\end{array}$ & Mw & Mn & $\mathrm{Mw} / \mathrm{Mn}$ & $\mathrm{TPC}^{* *}$ & ROO• & $\mathrm{H}_{2} \mathrm{O}_{2}$ & $\mathrm{ONOO}^{-}$ \\
\hline SF-pH12 & 12 & 10 & $4.99 \pm 0.10$ & 4438 & 661 & 6.71 & $278.5 \pm 11.3 \underline{a}$ & $3830.7 \pm 134.2^{a}$ & $30.0 \underline{a}$ & $2.4^{a}$ \\
\hline SF-pH10 & 10 & 8.3 & $4.71 \pm 0.07$ & 4254 & 702 & 6.05 & $317.5 \pm 26.5^{\text {ade }}$ & $3765.9 \pm 672.4^{\mathrm{ab}}$ & $30.5^{\mathrm{b}}$ & $2.8^{\mathrm{b}}$ \\
\hline SF-pH8 & 10 & 8.2 & $4.94 \pm 0.04$ & 9359 & 605 & 15.47 & $297.9 \pm 20.3^{\mathrm{a}}$ & $2749.7 \pm 223.8^{c}$ & $34.1^{\mathrm{c}}$ & $3.2^{\mathrm{c}}$ \\
\hline SF-pH6 & 10 & 8.13 & $4.66 \pm 0.02$ & 9068 & 878 & 10.3 & $284.7 \pm 18.6^{\mathrm{ac}}$ & $2868.9 \pm 307.4^{\mathrm{ac}}$ & $39.9^{d}$ & $2.3^{\mathrm{d}}$ \\
\hline SF-pH4 & 5 & 4.44 & $3.98 \pm 0.03$ & 488 & 342 & 1.43 & $269.1 \pm 18.8^{\mathrm{ac}}$ & $3646.3 \pm 238.1^{\mathrm{ab}}$ & $29.6^{\mathrm{e}}$ & $3.4^{\mathrm{e}}$ \\
\hline SF-pH2 & 1 & 0.55 & $3.54 \pm 0.09$ & 409 & 339 & 1.21 & $430.8 \pm 42.8^{b}$ & $10167.8 \pm 694.7^{d}$ & $14.9^{f}$ & $2.3^{\mathrm{d}}$ \\
\hline
\end{tabular}

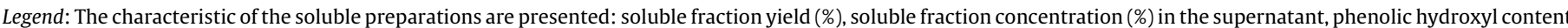

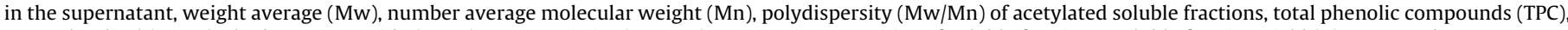

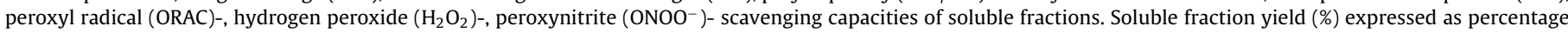

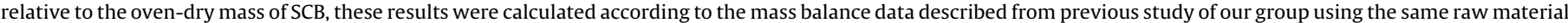
(Rocha et al., 2012b).

$n=3$. Note: the lignin concentration in the supernatant was estimated using Eq. (1) developed for the original lignin (AT).

** Total phenolic compounds expressed as mg gallic acid equivalent $\mathrm{g}$ lignin ${ }^{-1}$.

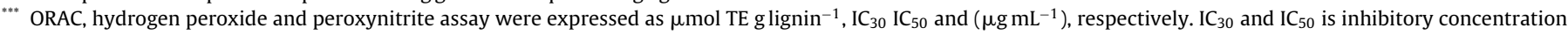

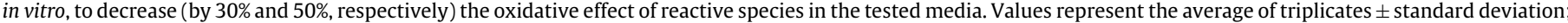
means followed by different letters in the same column differ statistically $(p<0.05)$ by the Tukey test. TE is Trolox equivalent.

Statistica 10.0 software at $95 \%$ confidence level. The results were expressed as the averages of triplicate experiments \pm SD (standard deviation). Differences were considered significant at $p<0.05$. A simple regression analysis with two independent variables was used for the ROS and RNS scavenging assay and TPC results. To establish the relationship among the TPC, Mw and the ROS and RNS scavenging assay results using a simple regression analysis with independent variables, we assumed an $\mathrm{x}$ factor $[\mathrm{TPC} / \mathrm{Mw}]$ and a y factor [ORAC/( $\left.\left.\mathrm{IC}_{30} \mathrm{H}_{2} \mathrm{O}_{2}{ }^{*} \mathrm{IC}_{50} \mathrm{ONOO}^{-}\right)\right]$.

\section{Results and discussion}

\subsection{Alkali treatment of steam-exploded SCB was effective to produce almost pure lignin}

Future biorefineries will integrate total biomass conversion processes and provide sustainable chains for producing fuels, power, and value-added products from biomass feedstock. Thus, a large amount of lignin will be generated from this biomass conversion process, making it available for different purposes. One factor that may restrict the use of lignin fractions to produce high-value-added materials and applications is the presence of organic and inorganic impurities. Several impurities such as sugars, silicates, sulfur, ash, proteins and other compounds derived from either raw materials or the delignification process can be produced after the pretreatment step (El Mansouri and Salvadó, 2006). The lignin examined in this study was produced from pilot-scale steam explosion pretreatment of SCB followed by alkaline delignification described by Rocha et al.(2012b). According to mass balance data, approximately $91 \%$ of the lignin contained in the steam-exploded solids was solubilized by delignification, resulting in a pulp with almost $90 \%$ of cellulose content. After acidification of the black liquor, $48.3 \%$ of the lignin originally contained in the raw material was recovered (Rocha et al., 2012b).

The acid-insoluble lignin (Klason lignin), acid-soluble lignin, sugars and decomposition products content after treatment of AT lignin with $72 \%$ sulfuric acid were determined. The percentage of acid-insoluble and acid-soluble lignin in AT lignin was $91.29 \pm 0.63 \%$ and $6.02 \pm 0.22 \%(w / w)$, respectively. Xylose was the only sugar detected in the hydrolysate at $0.19 \pm 0.07 \%(w / w)$. Furan aldehydes and acetic acid was not detected. The ash content determined in solid AT lignin was $2.92 \pm 0.03 \%(w / w)$.

The low amount of impurities in the starting material indicate that the approach based on steam explosion, followed by alkali precipitation, as described in Rocha et al. (2012b), produced almost pure lignin from SCB.

\subsection{Fractions with similar chemical structures were produced after the acidification steps}

The potential utilization of lignin to produce value-added compounds can be affected by heterogeneous nature of lignin. In this study, AT lignin (Fig. 1) was acidified with sulfuric acid $\left(1 \mathrm{~mol} \mathrm{~L}^{-1}\right)$ to yield soluble fractions, composed by lignins and LMW phenolic compounds, of homogeneous molecular weight and chemical functionality. This process is based on the solubility of lignins and LMW phenolic compounds at different $\mathrm{pH}$ values. The initial $\mathrm{pH}$ of the black liquor was 12 , and no precipitate formation was observed during the first solubilization step. The progressive decrease from $\mathrm{pH} 12$ to 2 , which was achieved by adding sulfuric acid $\left(1 \mathrm{~mol} \mathrm{~L}^{-1}\right)$, increased formation of precipitate and lightened the liquor's color. Two zones of high lignin precipitation yield were observed at $\mathrm{pH}$ 4 and $\mathrm{pH}$ 2. The resulting soluble fractions SF-pH4 and SF-pH2 presented polyphenolics contentration of $4.44 \mathrm{~g} \mathrm{~L}^{-1}$ and $0.5 \mathrm{~g} \mathrm{~L}^{-1}$, respectively (Table 1). In a similar experiment, García et al. (2009) used black liquor from Miscanthus sinensis pulping to precipitate lignin. The authors also observed different zones of meaningful precipitation, but over $\mathrm{pH} 10-11$, which was attributable to the silicates in the raw material, and $\mathrm{pH} 7-4$.

The soluble fraction yield (total amount of lignins and LMW phenolic compounds) in percentage of dry mass of SCB was calculated based on the mass balance of the pretreatment process (Rocha et al., 2012b). The highest yield obtained was $12 \%$ for SFpH12 (Table 1 ) because in this pH condition AT lignin was totally soluble. The lowest yield was obtained at SF-pH2, about $1 \%$.

It is known that oxidative degradation of ether linkages during alkaline treatment can increase hydroxyl groups content (Li and $\mathrm{Ge}, 2012)$. In this study, phenolic hydroxyl content was determined using differential scanning UV spectroscopy (Table 1). The SF-pH12 showed highest phenolic hydroxyl content (4.99\%), whereas the SF-pH2 showed the lowest value (3.54\%). Using a titration method, Mousavioun and Doherty (2010) obtained a notably similar value for the phenolic hydroxyl content (5.1\%) from lignin derived from SCB in natura after alkaline treatment.

The FTIR spectra of the soluble fractions are presented in Fig. 2. As shown in Fig. 2, the polysaccharide bands are not detected in the fractions. The results showed that the linkages between lignin and polysaccharides in sugarcane bagasse was completely cleaved 


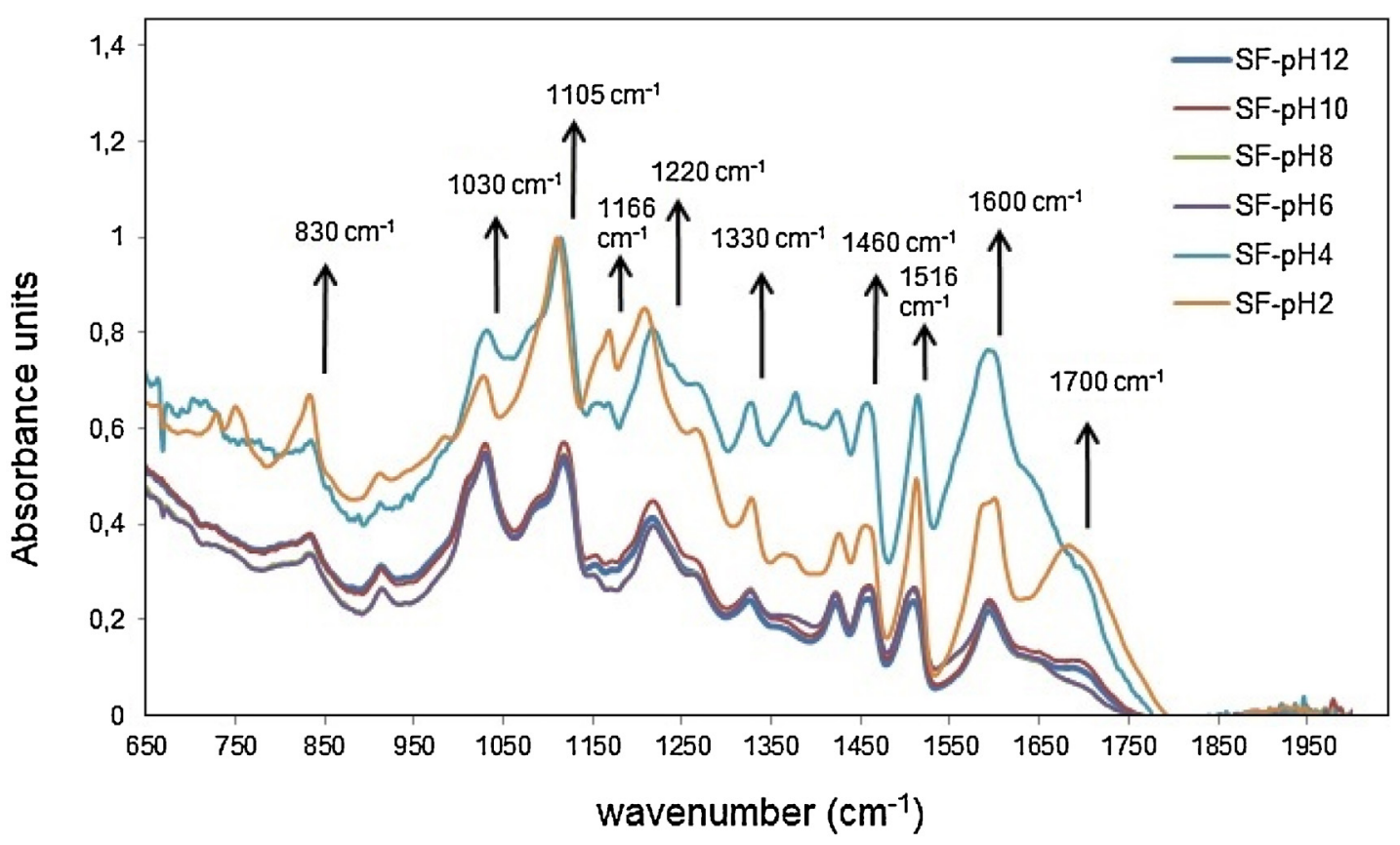

Fig. 2. FTIR spectra of soluble fractions.

during lignin alkali extraction from steam-exploded SCB described in Rocha et al. (2012b). The spectral patterns between SF-pH12 and 10 fractions and between SF-pH8 and 6 were notably comparable, suggesting that these fractions possessed similar lignin chemical compositions. A strong band around $1700 \mathrm{~cm}^{-1}$ observed for the SF-pH2 fraction has been assigned to carbonyl stretching group in unconjugation with the aromatic ring (Faix, 1994). García et al. (2009) observed that intensity of the carbonyl group increased after application of an acidification step to lignins obtained from apple tree pruning, which suggested oxidation or degradation of some phenolics groups. Probably, a significant number of polyphenols in the SF-pH2 fraction were likely oxidized. The bands at $1600 \mathrm{~cm}^{-1}$ and $1516 \mathrm{~cm}^{-1}$ which is attributed to aromatic skeleton vibrations and aromatic skeleton vibrations of guaiacyl and syringyl units, respectively, were observed for all fractions and with a higher intensity signals in SF-pH4 and 2 fractions (Faix, 1994). Asymmetric C-H deformations appear at $1460 \mathrm{~cm}^{-1}$ (Faix, 1994) in all fractions and higher intensity signals in SF-pH4 and 2 fractions. The band at $1330 \mathrm{~cm}^{-1}$ corresponds to the syringyl and guaiacyl condensed rings (Faix, 1994). Absorption at $1166 \mathrm{~cm}^{-1}$ only observed in SF-pH2 spectra indicates $\mathrm{C}=\mathrm{O}$ stretching in conjugated ester groups. The bands at $1105 \mathrm{~cm}^{-1}, 1030 \mathrm{~cm}^{-1}$ and $830 \mathrm{~cm}^{-1}$ attributed to aromatic $\mathrm{C}-\mathrm{H}$ in plane deformations (syringyl type) and $\mathrm{C}-\mathrm{H}$ out-of-plane vibrations in position 2,5 or 6 of guaiacyl units, respectivetly, were observed in all fractions spectra with stronger signals in SF-pH4 and 2 fractions (Faix, 1994).

The chemical structure of acetylated soluble fractions was studied using ${ }^{1} \mathrm{H}$ NMR spectrometry; the spectra are shown in Fig. 3. The SF-pH 12-6 fractions showed similar spectra with typical regions of lignin fragments (García et al., 2009), whereas the SF-pH 4-2 fractions showed a more defined profile with the region typical of LMW phenolics (Yoshimura et al., 2015). The integral of all signals between 6.4 and $8.0 \mathrm{ppm}$ can be attributed to aromatic protons. More specifically, the integrals of the signals centered at 6.6 and $6.9 \mathrm{ppm}$ observed only for SF-pH2 are assigned to aromatic protons in syringyl and condensed guaiacyl structures, respectively. The signal around $7.4 \mathrm{ppm}$ in SF-pH2 spectra and discreet for SFpH4 confirming the presence of $p$-hydroxyphenyl units and $\mathrm{C} \alpha=0$ groups in these fractions. The signal is attributed to the aromatic protons in positions 2 and 6 in structures containing a $\mathrm{C} \alpha=0$ group, to aromatic protons in positions 2 and 6 of $p$-hydroxyphenyl units conjugated with a double bond and also protons in $\mathrm{C} \alpha=\mathrm{C} \beta$ structures (Sun et al., 2013). The signal around $6.0 \mathrm{ppm}$ and $5.5 \mathrm{ppm}$ in SF-pH2 spectra is related to $\mathrm{H} \alpha$ in $\beta-\mathrm{O}-4$ and $\beta-5$ structures, respectively.

The integral of signals between 0.85 and $1.20 \mathrm{ppm}$, more intense in SF-pH4 and 2, can be attributed to the aliphatic moiety. Methoxyl protons $\left(\mathrm{OCH}_{3}\right)$ produced an intense signal centered at $3.75 \mathrm{ppm}$ in SF-pH12-6 fractions. Acetylation step was necessary to solubilize lignin and LMW phenolic compounds in $\mathrm{CDCl}_{3}$; however, derivatives displaying broad proton signals were produced between 1.65 and $2.70 \mathrm{ppm}$. In addition, aromatic and aliphatic acetyl groups were not shifted differently, which led to peaks overlapping.

\subsection{Large lignins aggregates, small nanometer-sized discs and polyphenolics clusters were found in the different lignin fractions}

To investigate the effect of acidification process on molecular weight of the AT lignin, soluble fractions obtained after acetylation protocol were first analyzed by GPC. Table 1 shows Mw, Mn and polydispersity (Mw/Mn) of soluble fractions.

The first two soluble fractions (SF-pH12 and SF-pH10) exhibit notably similar Mw ( $\sim 346 \mathrm{Da}), \mathrm{Mn}(\sim 680 \mathrm{Da})$ and polydispersity ( 6.4). According to Li and Ge (2012), similar Mw (4300 Da) and a lower polydispersity (2.86) were observed for sugarcane lignin derived from alkali process. However, Li and Ge (2012) used a different process for sugarcane bagasse pretreatment.

The SF-pH8 and SF-pH6 fractions exhibited the highest Mw ( $\sim 9200 \mathrm{Da})$ and polydispersity (10.3 and 15.5 , respectively). The highest Mw for these fractions can be attributed to acetylation step (required to perform GPC analysis) that could result in chemical modification of lignin. According to GPC data, the SF-pH4 and SF-pH2 fractions predominated LMW phenolics with low Mw ( $\sim 488 \mathrm{Da}), \mathrm{Mn}(\sim 340 \mathrm{Da})$ and polydispersity (1.32).

SAXS is an experimental technique widely used for structural characterization of colloidal or nanoscopic (organic or inorganic) 


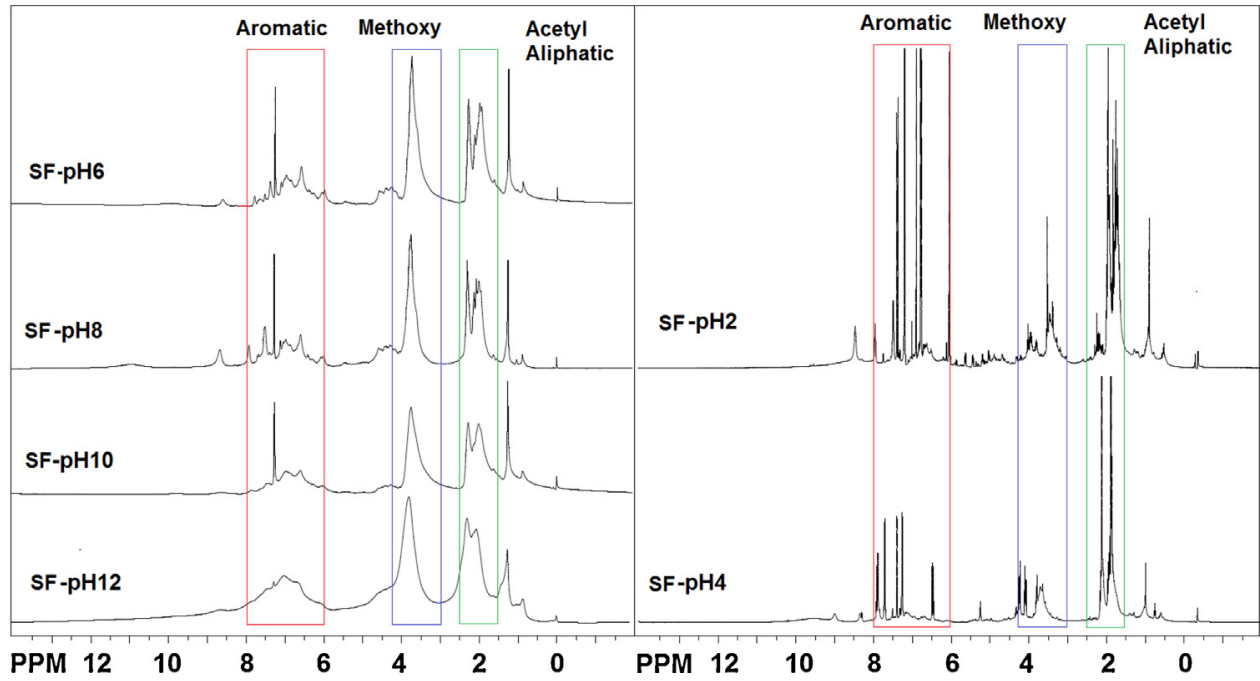

Fig. 3. ${ }^{1} \mathrm{H}$ NMR spectra of acetylated soluble fractions.

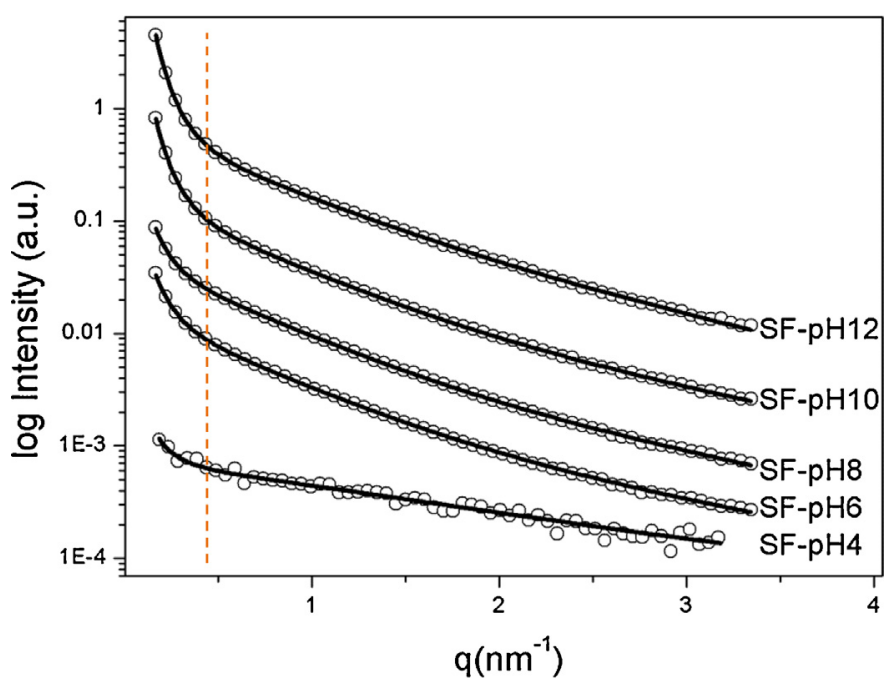

Fig. 4. Normalized SAXS in $\log (I) q v s$. $q$ scale corresponding to different soluble fractions samples. Experimental SAXS curves (symbols) and simulated SAXS functions modelled by SASFit (solid lines) exhibit excellent agreement.

particles in solution (Glatter and Kratky, 1982). This technique provides useful information about shape, dimension and size distribution of macromolecules in dilute solutions, as well as, the nature of molecular interactions. SAXS studies were previously applied to lignin by Harton et al. (2012) and others, to characterize lignin molecular architecture, shape, dimensions and intermolecular interactions.

We applied the SAXS technique to provide biophysical parameters from lignin and polyphenolics content of all soluble fractions describe in this remit. SAXS intensity data (function of the modulus of the scattering vector, $I(q)$ ) were obtained for each soluble fraction at three different concentrations of polyphenols: $2.5,5$ and $10 \mathrm{gL}^{-1}$. The SF-pH4 and 2 fractions were purified by GPC prior the analysis to eliminate the interfering inorganic components (see Supplementary material Fig. S1).

The results were displayed as $\log I(q) v s . \log q$ in Fig. 4. It was observed the same $q$-dependence for all three concentrations, indicating dilute regime even at highest concentration of polyphenols $\left(10 \mathrm{~g} \mathrm{~L}^{-1}\right)$.
SF-pH4 and SF-pH2 fractions yielded similar SAXS curves, but since the scattering curve corresponding from SF-pH2 fraction exhibited very high statistical errors, the SAXS data from this sample is not shown.

The qualitative analysis of SAXS curves plotted in Fig. 4 suggests that all soluble fractions exhibit typical behavior expected for nanoscopic macromolecules and their aggregates with two structural levels. At high $q$ range ( $q>0.4 \mathrm{~nm}^{-1}$ ), with negative curvature, it indicates the presence of rather small macromolecules or clusters (primary structure level). The intensity in the low $q$ range $\left(q<0.4 \mathrm{~nm}^{-1}\right)$, with positive curvature, implies occurrence of larger macromolecules or aggregates (secondary structure level).

The SASFIT package (Kohlbrecher, 2006) was used to fit simulated SAXS intensity functions to experimental curves. As approach for SAXS curves modeling, it was assumed that the system to be studied is isotropic, as well as, consists of diluted set of macromolecules or molecular clusters embedded in a homogeneous liquid solvent. It was also assumed that low-resolution shape of the primary macromolecules could be well described as a set of disks with unique thickness and distribution radius with lognormal distribution. The hypothesis of oblate ellipsoid, similar to disk-shaped lignin organization in solution, has been proposed previously (Vainio et al., 2004). The secondary structure level was considered to be composed of aggregates of lignin macromolecules with fractal structure.

The relevant parameters determined using the best fit procedure were the arithmetic average radius $\langle\mathrm{R}\rangle$, the standard deviation $\left(\mathrm{sd}_{\mathrm{R}}\right)$ and the thickness $(\mathrm{L})$ of the disk-shaped entities, along with the fractal dimension of molecular aggregates (D). The aggregates radius of gyration, which can be used for characterization of the average size of the aggregates (secondary structure level), were not determined because the minimum $q$ value accessible was not low enough in our experimental setup.

Comparison of the experimental scattering curves (symbols) with modeled scattering curves (solid line) is showed in Fig. 4. The structural parameters derived from best fitting procedure are reported in Table 2 . The average radius of the studied lignin and LMW phenolics is approximately the same for $\mathrm{pH}$ ranging from 6 to $10,<\mathrm{R}>=1.35-1.36$ and smaller for SF-pH12, $<\mathrm{R}>=1.13 \mathrm{~nm}$. SF-pH4 and SF-pH2 exhibited smaller average radius, $\langle\mathrm{R}\rangle=0.31 \mathrm{~nm}$, compared to the others fractions. The disk-shaped lignin are rather thick in SF-pH12 with $\mathrm{L}=0.81 \mathrm{~nm}$ and becomes progressively thinner in SF-pH4 and SF-pH2 with $\mathrm{L}=0.31 \mathrm{~nm}$. These findings indicate that progressive addition of sulfuric acid (consequent decrease in final 
Table 2

Structural parameters of different soluble fractions determined by SAXS.

\begin{tabular}{llllll}
\hline Sample & SF-pH12 & SF-pH10 & SF-pH8 & SF-pH6 & SF-pH4/pH2 \\
\hline$<\mathrm{R}>(\mathrm{nm})$ & 1.13 & 1.35 & 1.35 & 1.36 & 0.31 \\
sd $(\mathrm{nm})$ & 0.41 & 0.26 & 0.31 & 0.37 & 0.57 \\
L $(\mathrm{nm})$ & 0.81 & 0.66 & 0.71 & 0.58 & 0.31 \\
$\mathrm{D}$ & 2.80 & 2.71 & 2.15 & 2.18 & 2.19 \\
\hline
\end{tabular}

Legend: Average disk radius $<\mathrm{R}>$, radius standard deviation (sd), disk thickness (L) and fractal dimension (D).

$\mathrm{pH}$ ) caused fragmentation of lignin disk-shaped macromolecules and reduction of their thickness.

The fractal dimension of the lignin aggregates ranged from 2.80 to $2.71 \mathrm{~nm}$ in SF-pH12 and SF-pH10, respectively, and decreased during the acidification steps within $D=2.15-2.19 \mathrm{~nm}$ range. However, the values obtained for this parameter indicate that all studied samples exhibited mass fractal structure of lignin aggregates.

Lindström and Westman, 1982 explained the aggregation of alkali lignin in aqueous solutions by hydrogen bonding between neighboring lignin group carboxylic groups, ether oxygens, and hydroxylic groups. However, the same study with organosolv lignin and kraft lignin showed the intermolecular associative effects are governed by nonbonded orbital interactions ( $\pi-\pi$ interactions) among the benzene groups (Sarkanen et al., 1981). This type of interaction is a kind of $\pi-\pi$ aggregation of the aromatic groups that induces molecular aggregation. In the case of molecular aggregation governed by hydrogen bonding proposed by Lindström and Westman (1982) is a kind of aggregation that is not necessarily accompanied by $\pi-\pi$ aggregation of the aromatic rings.

Collectively, SAXS data corroborated with molecular weight distribution of soluble fractions determined by GPC analysis (Table 1). According to the structural parameters determined, the soluble fractions over the $\mathrm{pH}$ range of 12-6 contain rather large lignin aggregates, whereas the fractions with $\mathrm{pH} 4$ and $\mathrm{pH} 2$ consist of relatively small nanometer-sized LMW phenolics clusters.

\subsection{TPC, ROS and RNS scavenging assays correlated to the biophysical properties of soluble fractions}

Different in vitro assays were used to evaluate the effects of the soluble fractions on reactive oxygen and nitrogen species. In vitro systems have the advantage of being relatively simple and inexpensive to implement; however, it can only rank the antioxidant capacity for particular reaction system. Therefore, the correlation to in vivo systems must be further studied (Alves et al., 2010). Furthermore, it is considered prudent to use more than one antioxidant assay system to measure antioxidant capacities, since there may be distinct mechanisms involved that result in different outcomes depending on the test method employed (Magalhães et al., 2008). In this work, we evaluated the capacity of soluble fractions to serve as scavengers of peroxyl radical $\left(\mathrm{ROO}^{\bullet}\right)$, hydrogen peroxide $\left(\mathrm{H}_{2} \mathrm{O}_{2}\right)$ and peroxynitrite $\left(\mathrm{ONOO}^{-}\right)$.

The TPC and scavenging capacities of all soluble fractions are presented in Table 1. SF-pH2 showed the highest content of TPC, whereas the results were notably similar for samples SF-pH12 to 4. It is important to note TPC were determined by Folin-Ciocalteu colorimetric method. However, this method is not specific for phenolic compounds and estimates the total reducing capacity of certain sample, i.e. the Folin reagent reacts with any reducing compound and not only with the ones possessing phenolic hydroxyl groups (Everette et al., 2010).

SF-pH2 exhibited the highest values of scavenging capacity against peroxyl radical $\left(10167.8 \pm 694.7 \mu \mathrm{mol} \mathrm{TE}\right.$. g lignin $\left.{ }^{-1}\right)$ and hydrogen peroxide $\left(\mathrm{IC}_{30}=14.9 \mu \mathrm{g} \mathrm{mL}^{-1}\right)$. In the peroxynitrite scavenging capacity assay, SF-pH6 and SF-pH2 exhibited identical capacities $\left(\mathrm{IC}_{50}=2.3 \mu \mathrm{g} \mathrm{mL} \mathrm{L}^{-1}\right.$ ). It should be noted that the significance and relevance of an antioxidant evaluation strongly depend on the test method employed.

The correlation analysis between TPC and molecular weight was performed to understand the interrelationship between the soluble fractions and their antioxidant capacity. A good correlation was observed with the TPC and ROO• scavenging capacity $\left(R^{2}=0.89\right)$ and TPC and hydrogen peroxide scavenging capacity $\left(R^{2}=0.71\right)$, but correlation was not found between TPC and peroxynitrite scavenging capacity $\left(R^{2}=0.19\right)$. When all assays of scavenging capacity were compared with TPC and molecular weight, the linear correlation was $R^{2}=0.72$. These correlations suggest that TPC affects the antioxidant capacity, but more experimental data should be evaluated to confirm this hypothesis.

\subsection{GC-MS analysis identified LMW compounds with antioxidant capacity}

Based on the GC-MS analysis employed, it was possible to identify several phenolic and non-phenolic compounds in the soluble fractions (see Supplementary material Table T1). Cinnamic acid was identified in all fractions, as well as, ferulic acid, excepting for SF-pH12 and SF-pH2. Caffeic acid was identified only in SF-pH4 fraction. All compounds are reported in the literature as efficient natural antioxidants (Paiva et al., 2013; Damásio et al., 2013; Sova, 2012; Gülçin, 2006). Glycolic acid was present in all fractions. SFpH4 and SF-pH2 fractions showed oxalic and malic acid in its composition (Table S1), which are related with antioxidant properties (Kazemi et al., 2012; Kayashima and Katayama, 2002; Morreale and Livrea 1997).

It is important to mention that the value observed for TPC in disagreement with phenolic hydroxyl content for SF-pH2 (Table 1) can be attributed to the response of non-phenolic reducing substances present in this fraction. Glycolic, oxalic and malic acid are reducing substances that react with the Folin-Ciocalteu reagent and therefore are quantified as total phenolic compounds by the colorimetric method but not by the differential scanning UVspectroscopy method for phenolic hydroxyl content determination.

\subsection{Nearly monodispersed lignin and LMW compounds recovered in soluble fractions could be useful for further applications}

According to our data, the antioxidant capacity of soluble fractions may be attributed not only to the TPC and phenolic hydroxyl content but also to the ability of lignins to donate electrons (mechanism used in the inactivation of $\mathrm{H}_{2} \mathrm{O}_{2}$ ) and protons (mechanism used in the inactivation of $\mathrm{ROO}^{-}$and $\mathrm{ONOO}^{-}$) to radical species (Anouar et al., 2009; Huang et al., 2005). The SAXS data obtained for the SF-pH4 and 2 fractions suggest the occurrence of a significant resonance effect in the sample, because of the difficulties of primary beam attenuation and solvent subtraction. The free phenolic hydroxyl groups are essential to antioxidant capacity of lignin and LMW phenolics, because they can scavenge radicals by forming a stable phenoxyl radical (Barclay et al., 1997). There are substituents that positively affect the stabilization of phenoxyl radicals, such as methoxyl groups at the ortho position or conjugated double bonds, whereas a conjugated carbonyl group negatively affects the antioxidant capacity (Pan et al., 2006). Li and Ge (2012) evaluated the scavenging capacity of lignin that was extracted from SCB using different chemical procedures. They demonstrated that the radical scavenging activity was more strongly affected by the hydroxyl and methoxyl content than by the molecular mass and polydispersity. Based on a series of lignins that were isolated from deciduous and coniferous wood species, Dizhibite et al. (2004) demonstrated that high molecular weight, enhancement of heterogeneity and poly- 
dispersity were the factors that decreased the radical scavenging capacity of lignins. García et al. (2010) evidenced that different extraction processes could affect the antioxidant capacity of lignin obtained from Miscanthus sinensis. Moreover, Hussin et al. (2014) studied ethanol organosolv lignin from oil palm fronds and concluded that the radical scavenging capacity thereof was closely related to the average molecular weight and phenolic hydroxyl content. In addition, previous studies have demonstrated that lignins prepared from SCB exhibit antioxidant capacity similar to Epicatechin (Vinardell et al., 2008) (a well-known antioxidant compound) and lack cytotoxicity (Ugartondo et al., 2008).

Finally, even with the potential health benefits and industrial applications of lignins, the great heterogeneity of lignins makes it difficult to assign their antioxidant efficiency to specific structural components compared to the activities of chemically defined molecules such as tannins and flavonoids (Sakagami et al., 2005). In this study, the phenolic and non-phenolic molecules in obtained as soluble fractions can be considered high-value components, which were produced from a low cost acidification treatment of SCB lignin. Along with the nearly monodispersed lignin with unique structural features, these preparations could be attractive for development of range of products with antioxidant and antimicrobial properties. As a preliminary study not focused on process optimization, the yield of some promising fractions were low. To achieve complete integration of lignin from SCB in the biobased economy, more focus on the development of this process in a single step for example for lignin valorization is clearly desired. The mixtures of products that will arise from lignin processing constitutes also a challenge as well as new separation techniques for LWM phenolic compounds.

\section{Conclusions}

The acidification treatment of lignin stream, derived from steam-exploded sugarcane bagasse, resulted in low-polydispersity and low-molecular-weight preparations with high free-radical scavenging capacity. The soluble LMW compounds obtained at $\mathrm{pH} 2$ exhibited highest total phenolic yield and better antioxidant properties. According to the SAXS data, the soluble fractions obtained at $\mathrm{pH} 4$ and $\mathrm{pH} 2$ consisted of small nanometer-sized and low molecular weight polyphenols clusters, while in soluble fractions obtained at higher pHs wide nanoparticles and larger aggregates of lignin were predominant. Analysis by GC-MS identified in all fractions phenolic and non-phenolic compounds, which are well described antioxidants, such as cinnamic acid and glycolic acid, furthermore, the SF-pH4 and SF-pH2 fractions also presented oxalic and malic acid in its composition. We expect that our findings help to accelerate the development of new routes to overcome the inherent heterogeneity of lignin-enriched streams and allow the production of higher-value and sustainable commodities.

\section{Acknowledgments}

This work was financially supported by grants from National Counsel of Technological and Scientific Development-CNPq (442333/2014-5 and 310186/2014-5) and São Paulo Research Foundation-FAPESP (14/50371-8). LBB received a fellowship from São Paulo Research Foundation-FAPESP (2013/03061-0). We would also like to thank the staff of the National Center for Research in Energy ad Materials (CNPEM), Ana Carolina M. Zeri (LNBio/CNPEM), Maria Teresa Borges Pimenta and Karen Marabezi (CTBE/CNPEM). We gratefully acknowledge the provision of time on the facilities SAXS (LNLS), RMN (LNBio/CNPEM), LDB (CTBE/CNPEM).

\section{Appendix A. Supplementary data}

Supplementary data associated with this article can be found, in the online version, at http://dx.doi.org/10.1016/j.indcrop.2015.12. 013.

\section{References}

Alves, C.Q., David, J.M., David, J.P., Bahia, M.V., Aguiar, R.M., 2010. Métodos para determinação de atividade antioxidante em substratos orgânicos. Quim. Nova 33, 2202-2210.

Anouar, E., Kosinová, P., Kozlowski, D., Mokrini, R., Duroux, J.L., Trouillas, P., 2009. New aspects of the antioxidant properties of phenolic acids: a combined theoretical and experimental approach. Phys. Chem. Chem. Phys. 11, 7659-7668.

ASTM Methods, 1966. Standard Test Method for Lignin in wood. D.110656, pp. 396-398.

Ayyachamy, M., Cliffe, F.E., Coyne, J.M., Collier, J., Tuohy, M.G., 2013. Lignin: untapped biopolymers in biomass conversion technologies. Biomass Conv. Bioref. 3, 255-269.

Barclay, L.R.C., Xi, F., Norris, J.Q., 1997. Antioxidant properties of phenolic lignin model compounds. J. Wood Chem. Technol. 17, 73-90.

Beckman, J.S., Chen, J., Ischiropoulos, H., Crow, J.P., 1994. Oxidative chemistry of peroxynitrite. Methods Enzymol. 223, 229-240.

Benjamin, Y., Cheng, H., Görgens, J.F., 2013. Evaluation of bagasse from different varieties of sugarcane by dilute acid pretreatment and enzymatic hydrolysis. Ind. Crops Prod. 51, 7-18.

Bikova, T., Treimanis, A., Rossinska, G., Telysheva, G., 2004. On-line study of lignin behaviour in dilute alkaline solution by the SEC-UV method. Holzforschung 58 , 489-494.

Bizzo, W.A., Lenço, P.C., Carvalho, D.J., Veiga, J.P.S., 2014. The generation of residual biomass during the production of bio-ethanol from sugarcane, its characterization and its use in energy production. Renew. Sust. Energy Rev. 29 589-603.

Carvalho, D.M.D., Sevastyanova, O., Penna, L.S., Silva, B.P.D., Lindström, M.E., Colodette, J.L., 2015. Assessment of chemical transformations in eucalyptus, sugarcane bagasse and straw during hydrothermal, dilute acid, and alkaline pretreatments. Ind Crops Prod. 73, 118-126.

Chundawat, S.P.S., Beckham, G.T., Himmel, M.E., Dale, B.E., 2011. Deconstruction of lignocellulosic biomass to fuels and chemicals. Annu. Rev. Chem. Biomed. Eng. $2,121-145$.

Cui, C., Sun, R., Argyropoulos, D.S., 2014. Fractional precipitation of softwood kraft lignin: isolation of narrow fractions common to a variety of lignins. ACS Sustain. Chem. Eng. 2, 959-968.

Damásio, A.R.L., Braga, C.M.P., Brenelli, B.P., Citadini, A.P., Mandelli, F., Cota, J. Almeida, R.F., Salvador, V.H., Paixão, D.A.A., Segato, F., Mercadante, A.Z., de Oliveira Neto, M., dos Santos, W.D., Squina, F.M., 2013.

Biomass-to-bio-products application of feruloyl esterase from Aspergillus clavatus. Appl. Microbiol. Biotechnol. 97, 6759-6767.

Dias, M.O.S., Ensinas, A.V., Nebra, S.A., Filho, R.M., Rossell, C.E.V., Maciel, M.R.W., 2009. Production of bioethanol and other bio-based materials from sugarcane bagasse: integration to conventional bioethanol production process. Chem. Eng. Res. Des. 87, 1206-1216.

Dias, M.O.S., Junqueira, T.L., Cavalett, O., Cunha, M.P., Jesus, C.D.F., Mantelatto, P.E., Rossell, C.E.V., Filho, R.M., Bonomi, A., 2013. Cogeneration in integrated first and second generation ethanol from sugarcane. Chem. Eng. Res. Des. 91, $1411-1417$

Dizhibite, T., Telysheva, G., Jurkane, V., Viesturs, U., 2004. Characterization of the radical scavenging activity of lignins-natural antioxidants. Bioresour. Technol. 95, 309-317

Doherty, W.O.S., Mousavioun, P., Fellows, C.M., 2011. Value-adding to cellulosic ethanol: lignin polymers. Ind. Crops Prod. 33, 259-276.

dos Santos, P.S.B., Erdocia, X., Gatto, D.A., Labidi, J., 2014. Characterisation of kraft lignin separated by gradiente acid precipitation. Ind. Crops Prod. 55, 149-154.

El Mansouri, N.-E., Salvadó, J., 2006. Structural characterization of technical lignins for the production of adhesives: application to lignosulphonate, kraft, soda-anthraquinone, organsolv and ethanol process lignins. Ind. Crop. Prod. 24 $8-16$

Everette, J.D., Bryant, Q.M., Green, A.M., Abbey, Y.A., Wangila, G.W., Walker, R.B., 2010. Thorough study of reactivity of various compound classes toward the Folin-Ciocalteu reagent. J. Agric. Food Chem. 58, 8139-8144.

Faustino, H., Gil, N., Baptista, C., Duarte, A.P., 2010. Antioxidant activity of lignin phenolic compounds extracted from kraft and sulphite black liquors. Molecules 15, 9308-9322.

Faix, O., 1994. Fourier transform infrared spectroscopy. In: Lin, S.Y., Dence, C.W. (Eds.), Methods in Lignin Chemistry. Springer, Berlin, Germany, pp. 83-109.

García, A., Toledano, A., Andrés, M.A., Labidi, J., 2010. Study of the antioxidant capacity of Miscanthus sinensis lignins. Proc. Biochem. 45, 935-940.

García, A., Toledano, A., Serrano, L., Egues, I., Gonzalez, M., Marin, F., Labidi, J., 2009 Characterization of lignins obtained by selective precipitation. Sep. Purif. Technol. 68, 193-198.

Glatter, O., Kratky, O., 1982. Small Angle X-ray Scattering. Academic Press, London, ISBN 978-0122862809. 
Gomes, A., Fernandes, E., Silva, A.M., Santos, C.M., Pinto, D.C., Cavaleiro, J.A., Lima, J.L., 2007. 2-Styrylchromones: novel strong scavengers of reactive oxygen and nitrogen species. Bioorg. Med. Chem. 15, 6027-6036.

Gouveia, E.R., Nascimento, R.T., Souto-Marior, A., Rocha, G.J.M., 2009. Validation of methodology for the chemical characterization of sugar cane bagasse. Quim. Nova 32, 1500-1503.

Gülçin, I., 2006. Antioxidant activity of caffeic acid (3,4-dihydroxycinnamic acid). Toxicology 217, 213-220.

Hammersley, A.P., 1997. ESRF Internal Report, ESRF97HA02T, FIT2D: an introduction and overview.

Harton, S.E., Pingali, S.V., Nunnery, G.A., Baker, D.A., Walker, H., Muddiman, D.C., Koga, T., Rials, T.G., Urban, V.S., Langan, P., 2012. Evidence for complex molecular architectures for solvent-extracted lignins. ACS Macro Lett. 1 $568-573$.

Huang, D., Ou, B., Prior, R.L., 2005. The chemistry behind antioxidant capacity assays. J. Agric. Food Chem. 53, 1841-1856.

Hussin, M.H., Rahim, A.A., Ibrahim, M.N.M., Yemloul, M., Perrin, D., Brosse, N., 2014 Investigation on the structure and antioxidant properties of modified lignin obtained by different combinative processes of oil palm fronds (OPF) biomass. Ind. Crops Prod. 52, 544-551.

Kaur, R., Uppal, S.K., 2015. Structural characterization and antioxidant activity of lignin from sugarcane bagasse. Coll. Polym. Sci., http://dx.doi.org/10.1007/ s00396-015-3653-1.

Kazemi, M., Hadavi, E., Hekmati, J., 2012. Effect of salicylic acid, malic acid, citric acid and sucrose on antioxidant activity, membrane stability and ACC-oxidase activity in relation to vase life of carnation cut flowers. J. Plant Sci. 7, 78-84.

Kayashima, T., Katayama, T., 2002. Oxalic acid is available as a natural antioxidant in some systems. Biochim. Biophys. Acta 1573 (1), 1-3.

Kohlbrecher, J., 2006. Bressler, I. http://sans.web.psi.ch/SANSSoft/versions/sasfit 0.93 .3 .

Kuo, C.-H., Lee, C.-K., 2009. Enhanced enzymatic hydrolysis of sugarcane bagasse by $N$-methylmorpholine- $N$-oxide pretreatment. Bioresour. Technol. 100, 866-871.

Li, M.-F., Sun, S.-N., Xu, F., Sun, R.-C., 2012. Sequential solvent fractionation of heterogeneous bamboo organosolv lignin for value-added application. Sep. Purif. Technol. 101, 18-25.

Li, Z., Ge, Y., 2012. Antioxidant activities of lignin extracted from sugarcane bagasse via different chemical procedures. Int. J. Biol. Macromol. 51, 1116-1120.

Lindström, T., Westman, L., 1982. The colloidal behaviour of kraft lignin. Colloid Polym. Sci. 260, 594-598.

Ma, Pu, Gao, Ya, Zhai, Huamin, 2013. Fractionated wheat straw lignin and its application as antioxidant. BioResources 8, 5581-5595.

Magalhães, L.M., Segundo, M.A., Reis, S., Lima, J.L., 2008. Methodological aspects about in vitro evaluation of antioxidant properties. Anal. Chim. Acta 613, 1-19.

Mandelli, F., Brenelli, L.B., Almeida, R.F., Goldbeck, R., Wolf, L.D., Hoffman, Z.B. Ruller, R., Rocha, G.J.M., Mercadante, A.Z., Squina, F.M., 2014. Simultaneous production of xylooligosaccharides and antioxidant compounds from sugarcane bagasse via enzymatic hydrolysis. Ind. Crops Prod. 52, $770-775$.

Martínez, P.M., Bakker, R., Harmsen, P., Gruppen, H., Kabel, M., 2015. Importance of acid or alkali concentration on the removal of xylan and lignin for enzymatic cellulose hydrolysis. Ind. Crops Prod. 64, 88-96.

Maziero, P., Oliveira Neto, M., Machado, D., Batista, T., Cavalheiro, C.C.S., Neumann, M.G., Craievich, A.F., Rocha, G.J.M., Polikarpov, I., Gonçalves, A.R., 2012. Structural features of lignin obtained at different alkaline oxidation conditions from sugarcane bagasse. Ind. Crops Prod. 35, 61-69.

Morreale, M., Livrea, M.A., 1997. Synergistic effect of glycolic acid on the antioxidant activity of alpha-tocopherol and melatonin in lipid bilayers and in human skin homogenates. Biochem. Mol. Biol. Int. 42, 1093-1102.

Mousavioun, P., Doherty, W.O.S., 2010. Chemical and thermal properties of fractionated bagasse soda lignin. Ind. Crops Prod. 31, 52-58.

Paiva, L.B., Goldbeck, R., Dos Santos, W.D., Squina, F.M., 2013. Ferulic acid and derivatives: molecules with potential application in the pharmaceutical field. Braz. J. Pharm. Sci. 49, 396-411.
Pan, X., Kadla, J.F., Ehara, K., Gilkes, N., Saddler, J.N., 2006. Organosolv ethanol lignin from hybrid poplar as a radical scavenger: relationship between lignin structure, extraction conditions, and antioxidant activity. J. Agric. Food. Chem. 54, 5806-5813.

Ponomarenko, J., Dizhbite, T., Lauberts, M., Viksna, A., Dobele, G., Bikovens, O., Telysheva, G., 2015. Characterization of softwood and hardwood LignoBoost kraft lignins with emphasis on their antioxidant activity. Bioresources 9, 2051-2068

Ragauskas, A.J., Beckham, G.T., Biddy, M.J., Chandra, R., Chen, F., Davis, M.F., Davison, B.H., Dixon, R.A., Gilna, P., Keller, M., Langan, P., Naskar, A.K., Saddler, J.N., Tschaplinski, T.J., Tuskan, G.A., Wyman, C.E., 2014. Lignin valorization: improving lignin processing in the biorefinery. Science 344, http://dx.doi.org 10.1126/science.1246843.

Randhir, R., Lin, Y.-T., Shetty, K., 2004. Stimulation of phenolics, antioxidant and antimicrobial activities in dark germinated mung bean sprouts in response to peptide and phytochemical elicitors. Process Biochem. 39, 637-646.

Rocha, G.J.M., Gonçalves, A.R., Oliveira, B.R., Olivares, E.G., Rossell, C.E.V., 2012a. Steam explosion pretreatment reproduction and alkaline delignification reactions performed on a pilot scale with sugarcane bagasse for bioethanol production. Ind. Crops Prod. 35, 274-279.

Rocha, G.J.M., Martín, C., Silva, V.F.N., Gómez, E.O., Gonçalves, A.R., 2012b. Mass balance of pilot-scale pretreatment of sugarcane bagasse by steam explosion followed by alkaline delignification. Bioresour. Technol. 111, 447-452.

Rodrigues, E., Mariutti, L.R., Mercadante, A.Z., 2013. Carotenoids and phenolic compounds from Solanum sessiliflorum, an unexploited Amazonian fruit, and their scavenging capacities against reactive oxygen and nitrogen species. J. Agric. Food. Chem. 61, 3022-3029

Sakagami, H., Hashimoto, K., Suzuki, F., Ogiwara, T., Satoh, K., Ito, H., Hatano, T., Takashi, Y., Fujisawa, S., 2005. Molecular requirements of lignin-carbohydrate complexes for expression of unique biological activities. Phytochemistry 66, 2108-2120.

Sarkanen, S., Teller, D.C., Hall, J., McCarthy, J.L., 1981. Associative effects among organosolv lignin components. Macromolecules 14, 426-434.

Singleton, V.L., Orthofer, R., Lamuela-Raventes, R.M., 1999. Analysis of total phenols and other oxidation substrates and antioxidants by means of Folin-Ciocalteu reagent. Method Enzymol. 299, 152-178.

Sova, M., 2012. Antioxidant and antimicrobial activities of cinnamic acid derivatives. Mini Rev. Med. Chem. 12, 749-767.

Suguiyama, V.F., Silva, E.A., Meirelles, S.T., Centeno, D.C., Braga, M.R., 2014. Leaf metabolite profile of the Brazilian resurrection plant Barbacenia purpurea Hook. (Velloziaceae) shows two time-dependent responses during desiccation and recovering. Front. Plant. Sci. 5 (96), 1-13.

Sun, J.-X., Sun, X.-F., Sun, R.-C., Fowler, P., Baird, M.S., 2013. Inhomogeneities in the chemical structure of sugarcane bagasse lignin. J. Agric. Food. Chem. 51 6719-6725.

Sun, S.-L., Wen, J.-L., Ma, M.-G., Sun, R.-C., Jones, G.L., 2014. Structural features and antioxidant activities of degraded lignins from steam exploded bamboo stem. Ind. Crops Prod. 56, 128-136.

Ugartondo, V., Mitjans, M., Vinardell, M.P., 2008. Comparative antioxidant and cytotoxic effects of lignins from different sources. Bioresour. Technol. 99, 6683-6687

Vainio, U., Maximova, N., Hortling, B., Laine, J., Stenius, P., Simola, L.K., Gravitis, J., Serimaa, R., 2004. Morphology of dry lignins and size and shape of dissolved lignin particles by xray scattering. Langmuir 20, 9736-9744.

Vinardell, M.P., Ugartondo, V., Mitjans, M., 2008. Potential applications of antioxidant lignins from different sources. Ind. Crops Prod. 27, 220-223.

Wada, S., Iwamida, T., Iizima, R., Yabe, K., 1962. Fractional precipitation of kraft black liquor from spruce wood. Chem. High Polym. 19, 699-703.

Wexler, A.S., 1964. Characterization of lignosulfonates by U. V. spectrometry (direct and difference spectrograms). Anal. Chem. 36 (1), 213.

Yoshimura, M., Ninomiya, K., Tagashira, Y., Maejima, K., Yoshida, T., Amakura, Y., 2015. Polyphenolic constituents of the pericarp of mangosteen (Garcinia mangostana L.). J. Agric. Food Chem., http://dx.doi.org/10.1021/acs.jafc. 5b01771. 